\title{
Spectral Analysis of Heart Rate Variability During Mobile Phone Usage in First Year Medical Students
}

\author{
Rekha $^{1}$, Rashmi Ramanathan ${ }^{2}$, Jensy Sekar ${ }^{3}$, Ram Mohan $^{4}$, Kalpaka $^{4}$, S.Jeevithan ${ }^{5}$ \\ ${ }^{1}$ Assistant Professor, ${ }^{2}$ Associate Professor, Department of Physiology, KMCH Institute of Health Science and \\ Research, Coimbatore, ${ }^{3}$ Final MBBS Part I, Karpagam Faculty of Medical Sciences and Research, Coimbatore, \\ ${ }^{4}$ Tutor in Physiology, KMCH Institute of Health Science and Research, Coimbatore, ${ }^{5}$ Associate Professor, \\ Department of Community Medicine, KMCH Institute of Health Science and Research, Coimbatore
}

\begin{abstract}
Background: The electromagnetic radiations emitted by cellular telephones may influence the autonomic tone which modifies the functioning of the circulatory system.

Aim and Objectives: To estimate the effect of using mobile phones on heart rate variability (HRV) in first year medical students.

Method: ECG and HRV parameters are recorded in three periods, - when the subject is at rest without mobile phone (Period-I), with mobile phone kept on the left chest (Period-II) and when responding to a call by keeping the mobile over his right ear (Period-III) on 100 healthy subjects aged between 18 and 21 years of either sex.

Results: When the mobile was kept on chest or while attending a call,a decrease in high frequency (HF) in normalized units and increase in low frequency (LF) in normalized units and increase in the ratio of LF to $\mathrm{HF}$ (LF/HF) was observed in the frequency domain measures. Decrease in RR intervals, RMSSD and NN50 was observed in the time domain measures

Conclusion: The participants showed a higher sympathetic tone and a lower parasympathetic tone while attending a call. The study proved the intense effects of handset radiofrequency radiations on autonomic balance in healthy subjects.
\end{abstract}

Key words :Heart rate Variability, electromagnetic radiations, mobile phone usage.

\section{Introduction}

Recent years have witnessed unprecedented increase and ubiquitous use of mobile phone and enormous attention about its ill effects on human health. Presently, mobile phones are being used everywhere because these devices do not use the physical cable/wire that

\section{Corresponding author:}

Dr. Rashmi Ramanathan M.D., Associate Professor, Department of Physiology, $\mathrm{KMCH}$ Institute of health science and research, Coimbatore

Mail : rashmikumar82@gmail.com

Phone: 9486127040. is demanded for the communications purposes ${ }^{1}$. The intense use of mobile phones has led to cardiac disorders, malignancy, infertility,sleep disturbances, headaches, memory problems, and nervous disorders like changes in the electroencephalographic activity and brain tumours on long term usage. Electromagnetic fields emitted by cellular phones interfere with the work of cardiac pacemakers and other implantable medical devices ${ }^{2,3}$. So caution should be exercised when using smartphones around sensitive electro medical equipments in hospital intensive care units and on airplanes.

Electromagnetic waves are non-ionizing radiations which causes tissue heating or induce electrical currents in tissues which is the principal mechanism of interaction 
between radiofrequency energy and the human body Tissue heating is the best-established mechanism for RF radiation induced effects in biological systems ${ }^{4}$. Since heart is an electrically excitable tissue, more research is required to assess its susceptibility to radio-frequency electromagnetic radiation (RF-EMF).

Exposure levels : Mobile phones are low-powered radiofrequency transmitters, operating at frequencies between 450 and $2700 \mathrm{MHz}$ with peak powers in the range of 0.1 to 2 watts ${ }^{5}$. The present standards indicate that the maximum powers that the mobile phones is permitted to transmit are 2 and $1 \mathrm{~W}$ for 900 and 1800 $\mathrm{MHz}$ respectively ${ }^{6,7}$. High level EMF may change the complexity of cardiac system behaviour ${ }^{8}$.

Heart rate variability Heart rate variability (HRV) analysis helps to evaluate the equilibrium between the sympathetic and parasympathetic effects on heart rhythm by measuring the beat-to-beat variations of R-R interval ${ }^{9}$.

In response to public and governmental concern, WHO established the International Electromagnetic Fields (EMF) Project in 1996 to assess the scientific evidence of possible adverse health effects from electromagnetic fields ${ }^{10}$.

It is now known that among the prominent frequency bands in the HRV spectra, the high frequency (HF) component is attributed to the para-sympathetic influences on the heart and that the low frequency (LF) component is due to both the parasympathetic nervous system (PNS) and the sympathetic nervous system (SNS) activities ${ }^{11,12}$.

Heart rate variability has gained wide-spread acceptance as a clinical tool for the evaluation of cardiac autonomic changes. It was shown that the call with a mobile phone may change the autonomic balance in healthy subjects due to its electromagnetic field. But the exact contributions of the parasympathetic and the sympathetic divisions of the autonomic nervous system to this variability remain controversial. Therefore, the present study was undertaken to test the intense effects of handset radiofrequency radiations on cardiac autonomic modulation.

\section{Aim and Objectives}

1. To study the effect of radio-frequency electromagnetic radiation (RF-EMF) emitted from mobile phones on cardiac autonomic nervous system in first year MBBS students.

2. To compare the HRV parameters in individuals with and without smart phone radiations.

\section{Methodology}

After getting Institutional Ethical Committee clearance and informed consent from voluntary second year MBBS students, 100 first year MBBS students (male: 50, female: 50 ) in the age group between 18 and 21 years of either sex were included in the study. Students taking medications affecting cardio-respiratory response (anti psychotics, antidepressants, anti arrhythmic) or with any serious cardiovascular disease including arterial hypertension, ischemi/rheumatic heart diseases, diabetes mellitus, metabolic and neurological disorders which could influence the HRV analysis were excluded from the study. Detailed history taking, demographic data $\&$ vitals like BP, HR of all the participants were obtained.

\section{Pre-test preparations}

Subjects were instructed not to eat, drink, smoke, exercise \& play for at least an hour prior to the test. HRV recording was done between 9:00 and 11:00 am in a semidarkened, temperature controlled research laboratory. The subject was maintained at rest in supine position for a period of $10 \mathrm{~min}$. The standard procedures for shortterm HRV analysis were followed. The changes in the heart rate were measured on the polygraph by Recorders and Medicare System (RMS) polyrite D data acquisition system.

\section{Method of HRV analysis}

Then ECG and HRV parameters are recorded under following conditions.

1. When the subject is at rest without mobile phone for $3 \mathrm{~min}$ (Period-I)

2. When the mobile is kept over the front pocket or left chest for $3 \mathrm{~min}$ (Period-II)

3. When the subject is responding to a call by placing the mobile over his right ear for $3 \mathrm{~min}$ (Period-III)

These 3 conditions were studied at an interval of 5 min.We used Xiomi Redmi mobile phone for our research project. The highest SAR value for use of this device at the ear is $0.75 \mathrm{~W} / \mathrm{kg}$. The recorded HRV parameters are 
time domain and frequency domain measures.

The time domain parameters obtained during HRV measurements are 1) Mean RR i.e., the average of all RR intervals. 2) SDNN ie. The standard deviation of all NN intervals. 3) NN50 - It is the number of pairs of adjacent RR intervals differing more than $50 \mathrm{~ms}$. 4) RMSSD ie., the square root of the mean of the sum of the squares of differences between adjacent RR intervals. 5) Mean HR.

The frequency domain parameters obtained by Lomb periodogram are high frequency (HF, 0.15$0.4 \mathrm{~Hz}$ )), low frequency (LF 0.04-0.15 Hz), very low frequency (VLF), and LF: HF ratio. Artifacts were eliminated by computer-based artifact detection and beats were rejected if they varied by more than $40 \%$ from the preceding beat.
It is known that the efferent vagal activity is a major contributor to the HF component ${ }^{17,18}$ Likewise, it has been reported that RMSSD andPNN50 reflect short-term HRV and are predominantly influenced by the parasympathetic tone, whereas SDNN is influenced by both the sympathetic and parasympathetic tone and express long-term HRV.A predominance of sympathetic tone in cardiac activity contributes to LF component and it induces tachycardia and reduces beat-to-beat variations $\mathrm{LF} / \mathrm{HF}$ ratio is computed to analyze the predominant activity of the heart.

Statistical analysis was done by using the SPSS version 23. All the data were expressed in the form of mean + SD. One way ANOVA was used to test the significant difference among the 3 periods. $P<0.05$ was taken as statistically significant.

Table 1: Demographic characteristics of the study volunteers

\begin{tabular}{|l|l|l|l|}
\hline Parameters & Male $(\mathbf{n}=\mathbf{5 0})$ & Female(n=50) & P value \\
\hline Age (years) & $20 \pm 0.81$ & $19.96 \pm 0.90$ & 0.816 \\
\hline Height $(\mathrm{cm})$ & $164.34 \pm 5.965$ & $156.22 \pm 5.46$ & $0.000 * *$ \\
\hline Weight $(\mathrm{Kg})$ & $66.20 \pm 7.071$ & $48.10 \pm 7.33$ & $0.000 * *$ \\
\hline BMI $\left(\mathrm{Kg} / \mathrm{m}^{2}\right)$ & $24.49 \pm 2.05$ & $19.70 \pm 2.79$ & $0.000 * *$ \\
\hline
\end{tabular}

Table 2: Comparison of Frequency domain measures of Heart rate variability in three different conditions

\begin{tabular}{|c|c|c|c|c|c|}
\hline \multicolumn{2}{|l|}{ Parameter } & \multirow{2}{*}{$\begin{array}{l}\begin{array}{l}\text { Period I } \\
(\text { mean } \pm \text { SD })\end{array} \\
45.25 \pm 17.43\end{array}$} & \multirow{2}{*}{$\begin{array}{l}\begin{array}{l}\text { Period II } \\
(\text { mean } \pm \text { SD })\end{array} \\
65.55 \pm 24.28\end{array}$} & \multirow{2}{*}{ 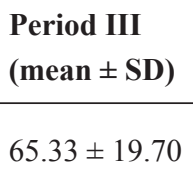 } & \multirow{2}{*}{$\begin{array}{l}\text { p value } \\
0.000^{* *}\end{array}$} \\
\hline & Males & & & & \\
\hline LF nu & Females & $42.33 \pm 19.07$ & $58.04 \pm 23.56$ & $83.44 \pm 32.79$ & $0.000 * *$ \\
\hline \multirow{2}{*}{ HF nu } & Males & $51.01 \pm 16.95$ & $34.20 \pm 15.84$ & $33.86 \pm 12.49$ & $0.000 * *$ \\
\hline & Females & $55.83 \pm 20.03$ & $50.96 \pm 18.61$ & $48.01 \pm 19.51$ & 0.129 \\
\hline \multirow{2}{*}{ LF/HF Ratio } & Males & $1.14 \pm 0.89$ & $2.41 \pm 1.88$ & $2.60 \pm 2.74$ & $0.000 * *$ \\
\hline & Females & $1.01 \pm 0.78$ & $1.34 \pm 0.77$ & $2.02 \pm 1.18$ & $0.000 * *$ \\
\hline \multirow{2}{*}{ HF Power } & Males & $40.11 \pm 20.24$ & $23.46 \pm 14.25$ & $27.38 \pm 12.25$ & $0.000 * *$ \\
\hline & Females & $40.98 \pm 21.81$ & $40.20 \pm 22.74$ & $41.19 \pm 27.72$ & 0.977 \\
\hline \multirow{2}{*}{ VLF Power } & Males & $29.08 \pm 23.01$ & $37.56 \pm 26.99$ & $26.63 \pm 21.40$ & 0.060 \\
\hline & Females & $22.37 \pm 20.44$ & $42.29 \pm 55.30$ & $40.20 \pm 26.78$ & 0.015 \\
\hline
\end{tabular}


Table 3: Comparison of time domain measures of Heart rate variability in three different conditions

\begin{tabular}{|l|l|l|l|l|l|}
\hline \multicolumn{2}{|l}{ Parameter } & $\begin{array}{l}\text { Period I } \\
(\text { mean } \pm \text { SD) }\end{array}$ & $\begin{array}{l}\text { Period II } \\
(\text { mean } \pm \text { SD) }\end{array}$ & $\begin{array}{l}\text { Period III } \\
(\text { mean } \pm \text { SD) }\end{array}$ & p value \\
\hline \multirow{2}{*}{ Mean RR (s) } & Males & $0.73 \pm 0.11$ & $0.68 \pm 0.13$ & $0.63 \pm 0.17$ & 0.375 \\
\cline { 2 - 6 } & Females & $0.71 \pm 0.10$ & $0.69 \pm 0.13$ & $0.72 \pm 0.13$ & 0.493 \\
\hline \multirow{2}{*}{ Mean HR } & Males & $89.24 \pm 27.21$ & $84.98 \pm 16.83$ & $92.42 \pm 26.24$ & 0.298 \\
\cline { 2 - 6 } & Females & $87.96 \pm 13.30$ & $90.34 \pm 19.14$ & $88.78 \pm 15.82$ & 0.759 \\
\hline \multirow{2}{*}{ SDNN (ms) } & Males & $73.87 \pm 45.27$ & $78.67 \pm 49.60$ & $84.13 \pm 42.06$ & 0.535 \\
\cline { 2 - 6 } & Females & $88.98 \pm 56.66$ & $79.41 \pm 47.41$ & $97.28 \pm 75.51$ & 0.344 \\
\hline \multirow{2}{*}{ RMSSD } & Males & $76.01 \pm 63.67$ & $64.47 \pm 34.84$ & $78.66 \pm 40.21$ & 0.293 \\
\cline { 2 - 6 } & Females & $97.32 \pm 77.20$ & $66.03 \pm 41.65$ & $112.09 \pm 98.71$ & $0.010^{*}$ \\
\hline \multirow{2}{*}{ NN50 (count) } & Males & $33.97 \pm 23.67$ & $33.14 \pm 21.67$ & $45.44 \pm 25.55$ & $0.017^{*}$ \\
\cline { 2 - 6 } & Females & $38.83 \pm 23.89$ & $38.03 \pm 24.76$ & $29.52 \pm 24.94$ & 0.113 \\
\hline \multirow{2}{*}{ pNN50 (\%) } & Males & $27.63 \pm 18.46$ & $34.45 \pm 34.86$ & $34.61 \pm 16.88$ & 0.277 \\
\cline { 2 - 6 } & Females & $33.28 \pm 20.04$ & $31.86 \pm 18.16$ & $39.36 \pm 34.03$ & 0.287 \\
\hline
\end{tabular}

Table 4: Comparison of bloodpressure among the subjects in three different conditions

\begin{tabular}{|l|l|l|l|l|l|}
\hline \multicolumn{2}{|l|}{ Parameter } & $\begin{array}{l}\text { Period I } \\
(\text { mean } \pm \text { SD) }\end{array}$ & $\begin{array}{l}\text { Period II } \\
(\text { mean } \pm \text { SD) }\end{array}$ & $\begin{array}{l}\text { Period III } \\
(\text { mean } \pm \text { SD) }\end{array}$ & p value \\
\hline \multirow{2}{*}{ SBP } & Males & $119.4 \pm 5.19$ & $127.12 \pm 4.48$ & $127.84 \pm 5.64$ & $0.000^{* *}$ \\
\cline { 2 - 6 } & Females & $110.4 \pm 8.94$ & $121.96 \pm 8.14$ & $117.22 \pm 8.91$ & $0.000^{* *}$ \\
\hline \multirow{2}{*}{ DBP } & Males & $77.96 \pm 5.17$ & $83.8 \pm 3.34$ & $83.26 \pm 4.45$ & $0.000^{* *}$ \\
\cline { 2 - 6 } & Females & $72.4 \pm 7.24$ & $78.04 \pm 6.37$ & $78.14 \pm 8.76$ & $0.000^{* *}$ \\
\hline
\end{tabular}

\section{Discussion}

Given the enormous number of smart phone users, it is essential to investigate and monitor any potential health impact of it and mainly on the cardiovascular system. ${ }^{13}$ Heart rate variability is a physiological phenomenon that reflects the autonomic functions ie.,parasympathetic and sympathetic influence on sinus node activity. In healthy individuals, parasympathetic tone predominates over sympathetic tone..

Among the frequency domain measures(table $2)$, LF power and LF/HF ratio in period $\operatorname{II}(2.41 \pm 1.88)$ and $\operatorname{III}(2.6 \pm 2.74)$ is increased in males than period 
$\mathrm{I}(1.14 \pm 0.78)$.This strongly emphasise that sympathetic tone has been increased when the mobile phone is kept on chest and while attending call than at rest and. LF power and LF/HF ratio in period III is increased in females than period I and II. This shows that sympathetic tone has been increased more while attending call than other conditions and it is consistent with the research work reported by Ryszard ${ }^{14}$ and Berkay Ekici ${ }^{15}$. HF power and HF nu was less in period I and II, ie. less parasympathetic activity which is a considerable cardiac morbidity. Difference in HF power, VLF power, and HF nu among the 3 periods are all statistically insignificant in females and VLF power among the 3 periods is statistically insignificant in males.

Among the time domain measures, (table 3 ) decrease in mean RR interval and increase in SDNN in period II and III in males strongly depicts that sympathetic tone is increased when the mobile phone is kept on chest and while attending a call. RMSSD was less in period II in both sex ie.,less parasympathetic activity This shows vagal modulation of the autonomic nervous system is decreased while the smart phone is kept on chest.and the sympathetic tone is increased ${ }^{16}$. There is statistically significant difference in RMSSD among the 3 periods in females and NN50 in males which signifies the decrease in vagal tone.

Similar results are derived in the study done by Kodavanji B ${ }^{17}$ et alemphasised that the time and frequency domain measures of the HRV have provided prognostic information and mobile users had a higher sympathetic tone and a lower parasympathetic tone as compared with the mobile nonusers.

Hemodynamic parameters like SBP,DBP (table-4) are increased in period II and III among both ssexes when compared to period I and it is consistent with the study reported by Vangelova ${ }^{18}$ et al that electromagnetic radiation exposure increases blood pressure. Heart rate (table-3) showed a steady increase in period II, III in both males and females. Thus it is evident that the phone usage may reflect a change in sympathovagal balancein favour of an increased sympathetic tone which may cause cardiac morbidity when used for prolonged duration.

The novelty our work was to study the effects of long-term exposure to Mobile phones on the cardiac electrical activity. Further randomized control trials should be carried out to show the unexplored effects of autonomic dysfunction on cardiovascular system so that we can prevent majority of cardiac illness by creating awareness among people especially the youngsters.

\section{Conclusion}

In this study, we have shown that the intense effects of handset radiofrequency radiations on autonomic balance in healthy subjects.Consequences of over usageof mobile phones for more than 15 years is lacking and this might warrant further research in this area.WHO also promotes research priorities for radiofrequency fields to fill gaps in knowledge through its research agendasWe conclude by saying that reserve the cell phones for shorter conversations and it is always better to prefer landline phones when available. Liberal use of headphones or keeping the phone little awaywhile attending a call and placing it at least three feet away from bed while sleeping might reduce the exposure to radio frequency energy.

Limitations of the study: First, the study population was relatively small and, therefore, the results could not be directly applied to the general population. Secondly, the study recorded HRV in short term. Inclusion of $24 \mathrm{~h}$ HRV would be more reliable and conclusive to validate the results.

Acknowledgment: Authors acknowledge the immense help received from the scholars whose articles are cited and included in references of this manuscript. Authors are also grateful to the Chairman and the Dean of this institution for their immense support and encouragement.

\section{Source of Funding : Self \\ Conflict of Interest : Nil}

\section{References}

1. Suhag AK, Larik RSA MangiGz, Khan M.Impact of Excessive Mobile Phone. Usage on Human Journal of Computer Science \& Systems Biology 2016;9(6):173-177.

2. Altamura G, Toscano S, Gentilucci G, Ammirati F. Influence of digital and analogue cellular telephones on implanted pacemakers. European Heart journal.1997;18:1632-41.

3. Barbaro V, Bartolini P, Donato A, Militello C.1999. Electromagnetic interference of analog cellular telephones with pacemakers: in vitro and in vivo studies.1999;22:626-634. 
4. Sofia Kottou, DimitriosNikolopoulos, Efstratios Vogiannis, DionysiosKoulougliotis, ErmioniPetraki,Panayiotis. How Safe is the Environmental Electromagnetic Radiation?Journal of Physical Chemistry and Biophysics. 2014;4(3)

5. Electromagnetic fields and public health: mobile phones 2014 ; [cited oct 8 2018]. Dpwnloaded from https://www.who.int/

6. Guidelines for limiting exposure to time-varying electric, magnetic, and electromagnetic fields (up to $300 \mathrm{GHz}$ ). International Commission on Non-Ionizing Radiation Protection. Health Phys 1998;74:494-522.

7. Media centre electromagnetic fields and public health:mobile phones. WHO $8^{\text {th }}$ October 2014 [cited $2^{\text {nd }}$ april 2019]. Downloaded from https://www.who. int/news-room/fact-sheets/detail/electromagneticfields-and-public-health-mobile-phones

8. Analysis of the Mobile phone effect on the Heart rate variability by using the largest lyapunovexponent.Journal of medical system, springer link.2010;34(6):1097-1103.

9. Karthik S and Pal GK. Sympathovagal imbalance in thyroid dysfunctions in females: correlation with thyroid profile, heart rate and blood pressure. Indian J PhysiolPharmacol. 2009;53(3):243-52.

10. What is the International EMF Project? World health organisation.downloaded from www.who. int/peh-emf/project-2016; Aug 4

11. Ori Z, Monir G, Weiss S, Sayhouni X, Singer DH. Heart rate variability: frequency domain analysis. CardiolClin 1992; 10: 499ÂA-537.
12. Akselrod S, Gordon D, Obel FA, Shannen DC, Barges AC, Cohen RJ. Power spectral analysis of the heart rate fluctuation: a quantitative process of the beat-to-beat cardiovascular control. Science 1981; 213: 220Â-22

13. Barutcu I, Esen AM, Kaya D, Turkmen M, Karakaya O, Sağlam M, etal. Do mobile phones pose a potential risk to autonomic modulation of the heart? Pacing ClinElectrophysiol 2011;34: 1511-4.

14. Ryszard Andrzejak, RafalPoreba, MalgorzataPoreba.The Influence of the Call with a Mobile Phone on Heart Rate Variability Parameters in Healthy Volunteers. Industrial Health ,Field Report 2008;46:409-417.

15. BerkayEkici and AslıTanınd1 .The effects of the duration of mobile phone use on heart rate variability parameters in healthy subjects Anatol J Cardiol 2016; 16: 833-8.

16. Malliani A, Pagani M, Lombardi F, CeruttiS. Cardiovascular neural regulation explored in the frequencydomain, 1991;84:1482-92.

17. Kodavanji B, Mantur VS, Kumar NA, Pai SR. A pilot study on long term effects of mobile phone usage on heart rate variability in healthy young adult males. J Clinical diagnosis Res.2012;6:346-9.

18. Vangelova K, Deyanov C, Israel M. Cardiovascular risk in operators under radiofrequency electromagnetic radiation. Int J Hyg Environ Health 2006;209:133-8. 